\title{
X. ZUBIRI FRENTE A LA NOCIÓN DE VALOR DE M. SCHELER
}

\section{ZUBIRI REGARDING OF SCHELER'S VALUE THEORY}

\author{
Pilar FERNÁNDEZ BEITES* \\ Universidad Complutense de Madrid
}

Resumen: Este ensayo analiza la crítica que hace Xavier Zubiri, en sus lecciones Sobre el sentimiento y la volición, a la noción de valor propuesta en la fenomenología de Max Scheler. Su objetivo final es acercar las posiciones de ambos filósofos, mostrando que la teoría del bien que propone Zubiri en dichas lecciones no maduras sólo adquiere todo su sentido si se entiende desde la noción fenomenológica de valor. Pero para ello hay que lograr introducir la noción de valor en la filosofía madura de Zubiri, de modo que el valor se dé en una peculiar "aprehensión primordial".

Palabras Clave: Scheler, sentimiento, aprehensión primordial, bien, realidad.

Авsтract: This paper analyzes Xavier Zubiri's criticism, in his lessons On feeling and volition (Sobre el sentimiento y la volición), of the notion of value in Max Scheler's phenomenology. His ultimate goal is to bring the positions of both philosophers closer together, showing that the theory of good that Zubiri proposes in these not-yetmature lessons only acquires all its meaning if it is understood from the phenomenological notion of value. But to do this we must manage to introduce the notion of value in Zubiri's mature philosophy, so that value is given in a peculiar "primordial apprehension".

KEY wORDs: Scheler, feeling, primordial apprehension, good, reality.

\footnotetext{
*Facultad de Filosofía, Universidad Complutense de Madrid, Ciudad Universitaria, s.n. 28040 Madrid. pbeites@ucm.es Profesora Titular de Universidad.
} 
En estas páginas voy a poner en relación la teoría del "bien" elaborada por el filósofo español Xavier Zubiri y la teoría fenomenológica del "valor" desarrollada por Max Scheler. Analizaré para ello la crítica que hizo Zubiri a la noción de valor de Scheler en sus lecciones no maduras Sobre el sentimiento y la volición (SSV), pero, sobre todo, intentaré lograr que dichas lecciones queden a la altura de su filosofía madura. Como dice A. Pintor Ramos $(1995,128)$ refiriéndose a dichas lecciones, "su integración en los cuadros más maduros de la filosofía de Zubiri exige (...) una verdadera prolongación del pensamiento zubiriano por caminos que él nunca recorrió explícitamente”. Y, por tanto, esto es lo que intentaré hacer aquí, pues voy a recorrer un nuevo camino no transitado por Zubiri, en el que mi objetivo final será acercar lo más posible la ética de Zubiri a la ética fenomenológica de Scheler.

Es cierto que cuando Zubiri se ocupa de la noción de valor scheleriana en su curso sobre "El problema del mal" de 1964 (SSV, 196-320), lo hace para criticarla con gran dureza, y en sus "Reflexiones filosóficas sobre lo estético" de 1975, llega a decir que "esta historia de los valores ha sido la tortura de la filosofía desde hace 70 años" (SSV, 357). Mas, pese a ello, creo que la distancia entre Zubiri y la fenomenología puede acortarse si al reconstruir la teoría ética de Zubiri desde la filosofía madura de la trilogía sobre la Inteligencia sentiente, logramos que la noción de valor quede situada en el nivel de la "aprehensión primordial". Y si, además, se presenta la fenomenología con un nivel de profundidad que evite ciertos malentendidos habituales por ambas partes.

Sabemos, en efecto, que Zubiri siempre se opuso a que la "realidad" que centra su filosofía se identificara con el "objeto intencional" de la fenomenología, pues estaba convencido de que el objeto fenomenológico es un mero nóema, que habría de situarse necesariamente, no en el nivel de la realidad, sino del "sentido" y sólo podría entenderse, por tanto, como "irrealidad" o idealidad. Pero quizás esto no sea del todo cierto, porque la fenomenología cuenta con un elemento equivalente a la zubiriana "aprehensión primordial de realidad", que es la "intuición", especialmente la percepción, donde se dan las "cosas mismas". El objeto de un acto perceptivo no es, según la fenomenología, un mero sentido irreal (como en un signo que mienta un objeto absurdo o inexistente), sino la cosa misma, que equivaldría a la realidad tal como la entendió el Zubiri maduro. En la percepción habría, sin duda, un "prius" por parte de lo dado, semejante al "quedar" de lo real en inteligencia, ya que en ella se produce una donación pasiva en la que se da la cosa que existe "realmente" (wirklich), de modo que su objeto no es en ningún sentido lo "puesto" o "construido" por el sujeto. En palabras 
del fundador de la fenomenología, E. Husserl, la percepción incluye una "protodoxa" o "creencia originaria", y el correlato por parte objetiva de la protodoxa es el "carácter de ser sin más", el del ser "real" (wirklich): "el carácter de ser sin más (el noemático "existe 'cierta' o 'realmente") [der Seinscharakter schlechthin (das noematische 'gewiß' oder 'wirklich' seiend)]" (Ideen I, \& 104, 240, tr. Ideas I, 251).

\section{La crítica de X. Zubiri a M. Scheler}

Aunque aquí no pueda exponer la teoría de los valores de Scheler que he desarrollado en otros lugares ${ }^{1}$, conviene recordar que su idea central es la tesis de la irreductibilidad del valor al ser, a ese ser "libre de valores" (wertfrei) del que hablaba el sociólogo Max Weber, que es un ser al margen del valor, un ser "neutral", al que, por mi parte, propongo denominar "ser teórico". Y para justificar esta irreductibilidad del valor, Scheler tuvo que mostrar la existencia de una peculiar donación afectiva cuyo objeto propio sería el valor.

En efecto, Scheler localiza unos actos originarios de acceso al valor, a los que denomina actos de "percibir afectivo" (Fühlen), y que se distinguen así de los actos sentimentales en general, a los que se refiere como "sentimientos" (Gefühle) (FE, 259 ss, tr. 356 ss). El término "Fühlen" literalmente significa sentir, pero lo traducimos como "percibir afectivo" para dejar claro que los valores son los correlatos originarios de dicho acto, al igual que la cosa teórica es el correlato de los actos de percepción externa. Esta distinción entre percibir afectivo y sentimientos (Füblen und Gefühle) se apoya en la noción básica de la fenomenología que es la "intencionalidad", porque los sentimientos que quedan fuera del percibir afectivo son los "estados sentimentales", que se denominan "estados" justamente para indicar la ausencia de intencionalidad propia de todo estado, bien sea afectivo o teórico. Los estados sentimentales son sentimientos ciegos, como la angustia o la pura rabia sin objeto, que son quizás los que más logran llamar la atención en nuestra vida cotidiana. Pero lo interesante es que frente a ellos encontramos los actos de percibir afectivo, que son sentimientos también habituales, aunque más difíciles de describir correctamente. Son sentimientos intencionales en los que se captan unos objetos peculiares, que son los valores; ya no son, por tanto,

1 Cf., por ejemplo, F. Beites, 2012. 
sentimientos ciegos, sino sentimientos que "ven", que ven el valor, que lo captan afectivamente.

Teniendo esto en cuenta, Scheler sostiene que entre el percibir afectivo y el valor se da la misma correlación que tiene lugar entre un acto teórico y su objeto, y, por tanto, puede atribuir al percibir afectivo una "función cognoscitiva", porque la intencionalidad abre un ámbito objetivo y esto es un modo de conocer; un conocer no teórico, sino afectivo. De este modo, se produce una ampliación de la razón, que deja de ser una "razón teórica" para convertirse en una "razón afectiva".

Pero veamos ya la crítica que Zubiri hace a la fenomenología de los valores de Scheler. En el mencionado curso sobre "El problema del mal", Zubiri distingue en ella dos tesis centrales: la "tesis de la irreductibilidad del valor", que acabo de exponer, y la "tesis de la independencia del valor". Por su parte, Zubiri admite, con Scheler, la irreductibilidad del valor, pero rechaza la independencia o no-fundamentación para poder mantener la idea clásica de que el valor ha de fundamentarse en la realidad: "La realidad es insuficiente para que haya valor -por eso son irreductibles-, pero es absolutamente necesaria para ello -y por eso no son independientes-" (SSV, 213). Empezando por el tema de la independencia, Zubiri acusa a Scheler de haber sostenido en El Formalismo que "las cosas son mero soporte (Träger) de los valores" (SSV, 208), en lugar de ser el fundamento de dichos valores; crítica que ya aparecía esbozada años antes en su conocido curso de ética "El hombre, realidad moral" (1953-4), donde Zubiri desarrolló lo que, en la nomenclatura que popularizó José Luis L. Aranguren, sería una "moral como estructura". Allí sostenía que Scheler habría convertido la realidad en el soporte de unas "cualidades irreales", que son los valores, y frente a esto defendía que la realidad ha de ser "raíz" y "fuente" del valor, nunca un mero "soporte" del valor, en ese sentido despectivo que Zubiri da al término scheleriano:

Scheler ha querido interpretar el bien como soporte de los valores. Pero el bien no es la cosa como soporte de los valores, sino al revés: como raiz de los valores, como fuente suya $(\mathrm{SH}, 358)$. La realidad no es meramente un soporte físico de unas cualidades irreales llamadas valores, sino que es su fuente real y efectiva por razón de las propiedades que tiene $(\mathrm{SH}, 383)$.

En "El problema del mal" retoma Zubiri esta misma idea y explicita la fundamentación del valor en la realidad afirmando que los valores lo son por las propiedades reales de las cosas: "la luz es serena precisamente por su tonalidad 
e intensidad" (SSV, 213). Además, recoge la dependencia del valor respecto a la realidad, que es su fundamento o su raíz o su fuente, en unas formulaciones interesantes cuando dice que "el valor no es sólo un valor en la cosa, sino un valor de la cosa” y que "la cosa no 'tiene' valor, sino que 'es' valiosa” (SSV, 214).

Así Zubiri va a proponer entender el bien como la realidad que "es" valiosa y va a elaborar su conocida articulación de la realidad en dos ámbitos: la "nuda realidad" y la "realidad valiosa", que sería equivalente al "bien": "La dualidad radical no se halla entre valor y realidad, sino que se inscribe dentro de la realidad, entre 'nuda realidad' y 'realidad valiosa'” (SSV, 216). La dualidad radical no es la "dualidad 'realidad-valor', sino la dualidad 'nuda realidad-realidad valiosa'. Dicho ahora con más precisión, es la dualidad 'nuda realidad-bien”” (SSV, 223).

Tras refutar la tesis scheleriana de la independencia del valor, Zubiri cree haber refutado la fenomenología de los valores (lo que le permite mantener en su ética la noción más clásica del bien, frente a la novedosa noción de valor). Pero, a mi juicio, Zubiri no logra su objetivo, porque es posible rechazar la tesis de la independencia o no-fundamentación del valor y, sin embargo, seguir defendiendo una ética de los valores: para ello basta con mantener la tesis de la irreductibilidad del valor. Esto es lo que hizo Husserl y lo que yo misma he propuesto en mi recuperación de la fenomenología de los valores. De este modo, la tesis zubiriana que funda el valor en la nuda realidad, tendría su paralelo en la tesis fenomenológica que funda el valor en el nivel teórico.

El propio Scheler ofrece en El formalismo una completa teoría del bien que se asemeja mucho a la de Zubiri. En ella el filósofo alemán se esfuerza en evitar que el bien se entienda como una cosa a la que se añaden accidentalmente ciertos valores, es decir, como una cosa que sería un mero "soporte" de valores en ese sentido despectivo que critica Zubiri. Por esta razón, Scheler deja de referirse al bien mediante la expresión habitual de "meras 'cosas valiosas' (bloße 'wertvolle Dinge)" (FE, 44, tr. 68) y forja la expresión técnica "cosa de valor” (Wertding) para caracterizar el bien: "Los bienes son por su esencia cosas de valor" (Güter sind ihrem Wesen nach Wertdinge) (FE, 32, tr. 53).

$\mathrm{Al}$ introducir esta terminología, Scheler hace un juego de palabras difícil de traducir, pues define las cosas valiosas como las cosas en tanto que "tienen" valores y luego afirma que para hablar del bien no basta con reconocer que hay esos “meros valores que 'tienen' las cosas”, esos “valores de la cosa” (Dingwerte), sino que debemos reconocer que hay las "cosas de valor" (Wertdinge). Así es como 
llegamos a la definición del bien como "cosa de valor" (Wertding) y no como una simple "cosa valiosa" (wertvolles Ding), que tiene valores pero que sólo los tiene "accidentalmente" (FE, 43; tr. 67): "debemos distinguir entre los bienes, es decir, las 'cosas de valor' (Wertdingen), y los meros valores que 'tienen' las cosas, que 'pertenecen' a las cosas, es decir, los 'valores de la cosa' (Dingwerte)” (FE, 42, tr. 66-7).

Esta definición del bien que nos propone Scheler es, en mi opinión, muy semejante a la de Zubiri. El filósofo español no quería entender el bien como cosa que "tiene" valor, sino como cosa que "es" valiosa. Pero esto es lo mismo que sostiene Scheler, porque él tampoco entiende el bien como una cosa que sólo "tiene" valores, como una mera "cosa valiosa", sino que, frente a ella, introduce el bien como "cosa de valor", que coincidiría, por tanto, con el bien zubiriano, con la cosa que "es" valiosa. Creo, además, que Scheler describe con brillantez esta cosa que "es" valiosa, cuando sostiene que el valor "penetra enteramente" en el bien. Lo hace en un texto que podría haber escrito el mismo Zubiri, pues en él afirma que el valor no se pega como un añadido accidental a una cosa ya constituida, no se construye "sobre la cosa", sino que el valor ha de configurar internamente las mismas propiedades cósicas hasta convertirlas en un bien; y de este modo Scheler está caracterizando el bien como pedía Zubiri, no como un valor "en" la cosa - "sobre" la cosa-, sino como un valor que, por así decirlo, impregna las propiedades cósicas del bien:

Se rechaza el considerar los 'bienes' como meras 'cosas valiosas'. Pues justamente les es esencial a los bienes que el valor no aparece sólo construido sobre la cosa (auf das Ding nur aufgebaut), sino que ellos se hallan penetrados enteramente (völlig durchdrungen) de valor (FE, 44, tr. 68-9).

\section{Eliminación del valor en la teoría del bien de Zubiri}

Aunque Zubiri funde el valor en la realidad, podría seguir defendiendo una fenomenología de los valores, pero vamos a ver a continuación cómo Zubiri, en su enfrentamiento con Scheler, pierde finalmente la tesis de la irreductibilidad del valor, que él mismo decía aceptar, y acaba, pues, por tirar al niño con el agua sucia: para mantener la fundamentación del valor, anula su irreductibilidad. 
Zubiri empieza por considerar el bien como el término formal de un acto de estimación, que equivaldría al "percibir afectivo" scheleriano: "El término formal del acto de estimación es el bien" (SSV, 222). También Ortega traducía como "estimar" el "sentir" o percibir afectivo de Scheler ${ }^{2}$, cuyo objeto es el valor; pero para Zubiri es directamente el bien, y no el valor, lo que constituye el objeto del acto de estimación. Y el filósofo vasco propone definir dicho bien como una "realidad en condición", siendo esa condición la condición de "estimanda" ("realidad en condición es, en efecto, simplemente bien", SSV, 222). Con este neologismo Zubiri quiere remarcar que el bien no es simplemente lo "estimado", que podría variar en los distintos sujetos, sino lo "estimando", lo que debe ser estimado por cualquier sujeto.

Podríamos esperar entonces que para Zubiri la condición de estimanda de la realidad consista en su ser "valiosa", porque así se mantendría la irreductibilidad del valor que Zubiri decía aceptar cuando reconocía que la nuda realidad es "insuficiente" para que haya valor. La nuda realidad está "allende el bien y el mal", es "ajena” a la diferencia entre bien y mal (SSV, 224) y, por tanto, la realidad valiosa debería añadir algo a la nuda realidad, que sería el valor: el valor haría que la realidad sea estimable, es decir, que sea un bien en sentido estricto y no una nuda realidad. Además, el ser valioso de lo real podría entenderse como quiere Scheler, pues para él el valor es un objeto intencional, un dato "objetivo", de manera que no es nunca lo que de hecho estima algún sujeto, sino lo que debe ser estimado; y esto es exactamente lo mismo que propone Zubiri ${ }^{3}$.

El problema es que Zubiri, en lugar de ligar la estimación al valor, va a elaborar una teoría muy sorprendente en la que la condición de estimanda se entiende como una "condición de respectividad", que consiste, no en que la realidad sea valiosa -en que en ella se funde el valor irreductible-, sino en que sea respectiva, respectiva a otra realidad. Otra realidad que, como precisa Zubiri, es la sustantividad humana (SSV, 233). Y si nos preguntamos por qué la respectividad ha de serlo respecto al hombre y no respecto a cualquier otra realidad, la respuesta de Zubiri es que la sustantividad humana tiene una peculiaridad que consiste en ser "una sustantividad que actúa para la sustantividad y en vista de la sustantividad" (SSV, 233).

\footnotetext{
${ }^{2}$ Ortega, 2004, 32 (cf. la interpretación de este texto en F. Beites, 2012).

${ }^{3}$ También U. Ferrer $(2010,109-114)$ señala con acierto las semejanzas entre Zubiri y Husserl en este punto.
} 
Pero si el bien se define como realidad en condición de respectividad a la sustantividad humana, parece claro que, como señaló en su momento Pintor Ramos $(1993,113)^{4}$, el bien queda situado en el nivel del "sentido", del "logos", y no en el nivel de la aprehensión primordial, en la que sólo estaría la realidad. Es cierto que, en sus lecciones no maduras, Zubiri todavía no utiliza esta terminología del logos que aparece en la trilogía, pero sí cuenta con la distinción entre la "cosa sentido" y la "cosa real", que había introducido en Sobre la esencia (y que sigue manteniendo en su filosofía madura, en IRE). En dicha obra Zubiri había entendido la cosa sentido como útil y ahora, en sus lecciones Sobre el sentimiento y la volición, se trataría de situar el bien en el mismo ámbito del sentido en el que estaban los útiles.

En efecto, Zubiri afirma, en Sobre el sentimiento y la volición, que las cosas en su nuda realidad son las cosas "que son 'meramente' actualizadas; las cosas inteligidas no hacen sino actualizar lo que ellas son de suyo en sus propiedades reales" (SSV, 229). Por el contrario, en las cosas sentido "la respectividad no es 'mera' actualización, sino actualización respecto de los actos vitales que el hombre va a ejecutar con ellas. Éstas son cosas cuya respectividad es el 'sentido' que tienen para la vida" (ibid.). En la cosa sentido no hay lo que podríamos denominar una "respectividad de mera actualización", sino una "respectividad de sentido", pues su respectividad es actualización, pero respecto de los actos que el hombre ejecuta con ella.

Centrándonos ya en el bien, recordamos que ha sido entendido como realidad en condición y, según Zubiri, "condición es la capacidad de la realidad para quedar constituida en sentido" (SSV, 231). Por tanto, el bien ańade a la realidad la respectividad de sentido ${ }^{6}$ y así el bien queda definido como realidad en condición de estimanda, siendo esa condición la respectividad de sentido respecto a la sustantividad humana: "se trata de que las cosas, precisamente por su condición, promuevan o no promuevan (...) el bonum de la sustantividad

\footnotetext{
4 Dicho con más precisión, es el nivel de la "trascendentalidad intelectiva del campo o mundo" y esto corresponde al nivel de la "simple aprehensión", que es el nivel del logos, frente a la "aprehensión primordial", a la que se denominaba "aprehensión simple" en la terminología no madura.

5 SE, 105.

6 Pero, aunque el hombre es el constituyente del sentido y esto podría hacer pensar en un relativismo del bien, Zubiri insiste en que es la cosa real la que por su condición queda en la estimación como algo real; y así la condición es una condición real de la cosa, de modo que "la condición no es sólo algo estimado, sino algo estimando" (SSV, 220-2).
} 
humana" (SSV, 254). De este modo, Zubiri hace depender el bien de las cosas del bien del hombre y, por consiguiente, ahora toda la tarea consiste en definir el propio bien del hombre.

Para ello Zubiri utiliza en sus lecciones la teoría clásica que identifica el bien con la felicidad, entendida como "plenitud", y afirma que el bien del hombre es la "plenitud formal e integral de su sustantividad" (SSV, 252). El problema es que cuando llega el momento de determinar con más precisión este bien del hombre, Zubiri renuncia a hacerlo desde su teoría filosófica: "Decir cuál es objetivamente el bonum intencional de mi propia sustantividad, eso es un asunto de ética. No es nuestro tema", dejando la realidad de la sustantividad humana "determinada de distintas maneras según las éticas". Para indagar sobre el bien del hombre, podríamos recurrir al citado curso de ética donde Zubiri desarrolla su moral como estructura. Pero, aunque allí ya identificaba el bien con la felicidad como plenitud o "perfectio" (SH, 390-1), tampoco intentaba determinar esta noción clásica, sino que, muy al contrario, defendía que el bien ha de quedar "constitutivamente indeterminado", por tratarse de un problema de la "razón" que permanece siempre abierto9. Y con el bien del hombre ha de quedar indeterminado todo el bien, ya que los otros bienes son respectivos al bien del hombre ( $\mathrm{SH}, 404)$.

Desde luego, la determinación cada vez más completa del bien ha de ser también un tema del logos y la razón, tal como se propone en la filosofía madura de Zubiri ${ }^{10}$, pero aquí nuestro autor parece dejarlo en manos de las distintas éticas empíricas. Y si esto es así, si todo el bien queda indeterminado y al albor de las distintas éticas empíricas, ya podemos entender por qué la ética filosófica de Zubiri puede considerarse una moral como "estructura", opuesta a una moral como "contenido": porque en ella se renuncia a dar contenido al bien, es decir, no se determina a qué debemos llamar bien. Siguiendo a Diego Gracia $(2007,382)$, podemos calificarla como una ética "formal", de modo que la ética zubiriana sería

\footnotetext{
7 SSV, 264. Cf. también p. 252.

8 SSV, 264. Cf. también p. 271.

9 "La inteligencia tiene que considerar lo que es eso de la felicidad en ese ejercicio ulterior de la inteligencia que es la razón" $(\mathrm{SH}, 412)$.

10 El "sentido" del que se ocupa el logos de la trilogía es más complejo que el de la "cosa sentido”. El sentido propio del logos abarca la simple aprehensión (percepto, ficto y concepto) y la aprehensión judicativa (la afirmación o juicio), y en él se pone la realidad en respectividad a la inteligencia del hombre, que construye la simple aprehensión y la afirmación. Podríamos decir, quizás, que el bien situado en el ámbito de la cosa sentido tendría algo así como un "sentido práctico", ya que se trata de poner la realidad en respectividad a la vida práctica del hombre.
} 
una "proto-moral" basada en un bonum formal que es la felicidad. Y Gracia considera que esta propuesta merecería llevar el nombre de "ética formal de bienes", como alternativa a la "ética material de valores" defendida por la fenomenología (ibid., 377).

Pero hemos de ver con cuidado en qué consiste esta supuesta alternativa zubiriana a la ética de los valores, porque al haber eliminado la noción material de valor a favor de un bien meramente formal, creo que podemos afirmar que su filosofía "se desliza" sobre el problema del valor y se queda anclada en una noción de bien que es reductible a realidad y recuerda por ello el bien de la tradición aristotélicotomista, en la que se defiende la tesis de la convertibilidad entre el ser y el bien.

Justamente esta tesis clásica de la convertibilidad es la que pretendía superar la fenomenología con su teoría de la irreductibilidad del valor, porque si el bien se reduce al ser, el mal queda convertido en un no ser, de modo que el mal simplemente no sería, no habría el mal (tesis clásica de la negatividad del mal). El propio Zubiri reconoce que su bien es un bien "no dual", un bien que no admite contrario, que es previo a la diferencia entre el bien y el mal. Frente a esto, en la ética de los valores se sostiene el carácter dual del valor, se sostiene, pues, que la realidad puede ser valiosa, pero también disvaliosa y más o menos valiosa; y así, al contar con valores o disvalores irreductibles a la realidad, dicha ética puede hacerse cargo del problema del mal. Zubiri, sin embargo, al renunciar al valor, no va a poder enfrentarse a este espinoso problema del mal, y tampoco estará en condiciones de solucionar otras cuestiones más básicas, que expongo a continuación.

\section{Algunas dificultades en la ética de Zubiri}

Zubiri ha definido el bien como condición de respectividad a la sustantividad humana, de modo que lo que el bien añade a la realidad de las cosas es el sentido, la utilidad que tienen para la vida humana o, dicho de otra forma, el bien de las cosas es su utilidad. Pero, como es sabido desde antiguo, el bien útil, lo bueno como medio, remite necesariamente al bien intrínseco, a lo bueno como fin, respecto a lo cual resulta útil lo útil. Por consiguiente, Zubiri necesita contar en su ética con el bien del hombre, que sería el único candidato a bien intrínseco, desde el cual se entendería el bien de las cosas. El problema es que, según la definición 
del bien que elabora Zubiri para distanciarse de Scheler, el bien del hombre ha de consistir, de nuevo, en que la realidad del hombre sea respectiva a otra realidad, sólo que ahora esa otra realidad es la misma realidad humana y, por tanto, el bien del hombre consiste en que la sustantividad humana sea respectiva a sí misma como realidad (y no en que sea respectiva al bien intrínseco del hombre, pues ese bien es el que se define como respectividad a una realidad).

Al formularlo de este modo, creo que ya se ve que en la teoría zubiriana el bien del hombre ha quedado reducido a la nuda realidad humana -que está en respectividad respecto a ella misma-. Aquí es donde se consuma, pues, la pérdida de la irreductibilidad del valor. Y, si esto es así, ahora todo el problema de la ética consistirá en determinar qué es esa realidad humana con la que se ha identificado el bien.

Como sabemos, Zubiri ya no define al hombre recurriendo a la noción clásica de "naturaleza" humana, sino que lo entiende ante todo como un hacerse libre en el que el hombre se configura a sí mismo -en esto consistiría principalmente la respectividad del hombre respecto a sí mismo-. Según dice Zubiri, el hombre no tiene sus propiedades ya dadas "por naturaleza", sino que las tiene "por apropiación"; el hombre para ser hombre tiene que "apropiarse sus posibilidades" libremente, definiendo así quién quiere llegar a ser. Pero si la realidad del hombre consiste sobre todo en su libertad, no debe sorprendernos que el bien formal de la "proto-moral" del primer Zubiri quede identificado con la libertad. En ella la dimensión moral del hombre residiría en su libre autorrealización, que llevaría a esa "plenitud" o felicidad, con la que ya antes nombrábamos el bien formal. O, si introducimos otro término de Zubiri, el bien del hombre consistiría en estar "en buena forma” (SH, 407), en tener la fuerza necesaria para llevar a cabo nuestra propia vida. Esto es lo que Zubiri ve reflejado en la interesante expresión castellana del "estar desmoralizado", porque cuando no somos capaces realizar nuestros proyectos, cuando estamos cansados o disgustados porque las cosas no nos salen bien, es cuando decimos que estamos desmoralizados. No tenemos ganas de nada; nos hemos quedado sin energía para continuar la tarea moral de construir nuestra vida; nos hemos quedado, pues, sin-moral: des-moralizados ${ }^{11}$.

Esta posición de Zubiri, en la que se deja notar la influencia de la propuesta existencialista de Heidegger, resulta en principio muy atractiva. El problema reside

11 "Cuando una persona está fatigada, cuando ha tenido un disgusto, se dice que está desmoralizada” (SH, 363). 
en que, al haber prescindido en ella de la noción de valor, estaríamos hablando aquí de una libertad que no está orientada por el bien, porque el bien que debería orientar la libertad ha quedado identificado con la libertad misma: el bien del hombre es su realidad, que consiste en el hecho de ser libre, de modo que el bien ya no es un dato previo a la libertad y por ello capaz de orientarla, sino que el bien se reduce a la libertad misma -o a la voluntad, dicho en términos clásicos-. Y caeríamos, por tanto, en una especie de voluntarismo relativista de corte heideggeriano o nietzscheano, porque lo cierto es que la libertad necesita contar con el valor para sustituir al telos que proporciona la naturaleza clásica ${ }^{12}$, de modo que, sin la apertura al valor, la libertad se convierte en la mera "libertad negativa" (liberum arbitrium indifferentiae) propia del voluntarismo.

La libertad negativa es una autonomía mal entendida, que consiste en el decidir yo sobre mi vida, sin dejarme determinar por nadie y sin contar con ninguna idea previa del bien, porque, según esta visión insuficiente de la libertad, el bien sólo pondría barreras a mi libre construirme a mí mismo. Pero en ética no podemos renunciar a la "libertad positiva", que es la orientada por el bien; por un bien que no coarta o coacciona la libertad (ya que siempre hay la opción de decidirse por el mal), sino que tan sólo orienta la libertad y así da sentido y cuerpo a la libertad. Esto es lo que se defiende en la ética de los valores, donde la moralidad no se reduce a forjar libremente nuestra vida, sino en orientar esa libertad hacia el bien, en acercarla al valor y alejarla del disvalor. El asesino o el ladrón de guante blanco están ejecutando con fuerza su libertad, pero no por ello son moralmente buenos, porque el bien moral no reside en tener que hacerse uno a sí mismo, sino en decidirse uno mismo a favor de los valores y en contra de los disvalores.

Dicho de otro modo, si aceptamos que el bien del hombre, su felicidad, consiste en la misma ejecución de la libertad, esto implica que cualquier hacerse del hombre sería igualmente bueno o feliz y así los términos "bueno" o "feliz" habrían perdido su significado. En efecto, todo hombre por el hecho de ser libre sería feliz en el sentido formal de la moral como estructura, pero entonces la palabra "felicidad" ya no significaría nada, pues hablar de un hombre feliz sólo cobra sentido cuando hay la posibilidad de que haya un hombre infeliz, es decir, cuando podemos determinar la diferencia de contenido entre la felicidad y la infelicidad; cosa que sólo sucede si la felicidad o el bien es un valor material que

\footnotetext{
${ }^{12}$ Valor ligado a la "esencia" o naturaleza del hombre, que Scheler entiende como un "ordo amoris".
} 
se opone al disvalor, y no es ese bien formal no dual que Zubiri quiso introducir para lograr distanciarse de Scheler ${ }^{13}$.

Por todo esto, creo que hemos de recuperar en nuestros días la noción de valor a la que Zubiri quiso renunciar, porque el voluntarismo al que podría verse abocada la ética de Zubiri encaja perfectamente en el mundo posmoderno actual, pero queda en las antípodas de las intenciones básicas del propio Zubiri.

\section{Hacia una reformulación de la teoría zubiriana del bien}

Para incorporar el valor a la ética de Zubiri, propongo reconstruir la moral como estructura del primer Zubiri desde el esquema maduro de la trilogía y situar el valor en el nivel de la "aprehensión primordial de realidad". Antonio González (1995, 193-4) acierta al indicar que, en la exposición del Zubiri no maduro, el bien como condición de estimanda podría hacerse corresponder al nivel de la aprehensión primordial, dado que el paso al nivel del sentido se produciría sólo en el momento en el que Zubiri introduce la condición de respectividad, que es a partir del parágrafo tercero. Pero, como hemos visto, no es esto lo que quiso defender el propio Zubiri, pues los dos primeros parágrafos ${ }^{14}$, en los que aparece la condición de estimanda, son precisamente los dedicados a criticar la noción de valor, para poder ofrecer después su alternativa a dicha noción, que consiste en reducir la condición de estimanda a condición de respectividad.

Por ello, mi propuesta es mantener el acto de estimación en el plano de la aprehensión primordial, sin relegarlo al nivel del sentido, pero esto exige "ampliar"

\footnotetext{
13 Conviene quizás señalar que, aunque es cierto que Zubiri se dejó influir por Heidegger, siempre defendió, frente a él, una "esencia" humana irreductible a la mera "existencia". Y Zubiri parece querer incluir en ella la felicidad cuando la entiende como posibilidad siempre "ya apropiada" (SH, 395, 401), pero esta felicidad tendría que entenderse como valor irreductible a la realidad humana (y ligarse al resto de valores abiertos en el ordo amoris).

14 En ellos no hay la dualidad entre bien y mal, sino sólo la "línea del bien" y, por ello, podrían corresponder, según A. González, al nivel de la aprehensión primordial. Pero, como he intentado mostrar, el problema es que no se puede hablar del bien sin hablar del mal, es decir, que no puede haber un bien no dual; aunque, desde luego, pueda defenderse que el bien es previo al mal y en este sentido podría entenderse la "línea del bien" zubiriana.
} 
dicha aprehensión de modo que no sea mera intelección teórica de nuda realidad. En efecto, lo aprehendido por la inteligencia en aprehensión primordial es, según Zubiri, la "realidad", pero nosotros debemos precisar que esa realidad no puede ser la nuda realidad que acaparó finalmente toda la filosofía de Zubiri, sino una "realidad ampliada" que incluya el valor. Además, nos damos cuenta de que sólo la realidad ampliada permite mantener la irreductibilidad del valor que defendía Zubiri y, con ella, la distinción central entre la nuda realidad y la realidad valiosa, porque si dicha distinción se hace "dentro de la realidad", esta realidad ha de entenderse como una realidad en sentido "amplio", que incluye el valor (valor que no se reduce a nuda realidad, aunque se funde en ella).

El problema es que, para poder ampliar la realidad -o el ser, que incluiría no sólo el ser teórico, sino lo que Scheler denomina el "ser-valor" (Wert-sein)-, Scheler tuvo que recurrir a un ámbito afectivo en el que se da originariamente el valor, y esto es lo que no hace Zubiri, pues él no llegó a reconocer en su obra la dimensión intencional del sentimiento. En sus lecciones no maduras la estimación no es una "percepción afectiva" del valor, sino un aprehender la realidad en respectividad a otra realidad ${ }^{15}$. Y la mayor dificultad consiste en que el Zubiri maduro continúa relegando el sentimiento a un segundo plano, de modo que en su trilogía sigue presente el denominado "inteleccionismo" zubiriano, en el que el sentimiento queda situado fuera de la aprehensión primordial, que consistiría en mera "intelección": "Sólo porque hay aprehensión sentiente de lo real (...) hay sentimiento y volición" (IRE, 283). Es, por tanto, este inteleccionismo el que tendríamos que superar nosotros, incluyendo el sentimiento en la misma aprehensión primordial, es decir, en la misma intelección, y así lograríamos la necesaria ampliación de la intelección, paralela a la ampliación de la realidad ${ }^{16}$.

Se trataría de defender que en la aprehensión primordial hay la aprehensión o intelección teórica en la que se actualiza la nuda realidad y hay también, un

15 En sus "Reflexiones filosóficas sobre lo estético", Zubiri se interesa algo más por el ámbito sentimental (por la "fruición") y sigue así la estela kantiana, pues también Kant concedió una mayor relevancia al sentimiento en el plano estético que en el ético.

16 Gracia $(2013,102)$ sostiene que, al proponer un inteleccionismo frente al "intelectualismo", Zubiri incluiría en él el momento del sentimiento y la volición, pero, a mi juicio, con su neologismo Zubiri sólo quiere evitar la logificación de la inteligencia (su restricción al nivel predicativo del logos). Según Gracia, la formalidad de realidad zubiriana incluiría ya la formalidad emocional y volitiva (ibid., 99) y, desde luego, es cierto que la formalidad de realidad puede incluir la formalidad afectiva (aunque no la volitiva), pero esto sucede únicamente si se introduce en la teoría de Zubiri la noción de valor tal como aquí estoy proponiendo. 
acto de "estimación", estrictamente afectivo, en el que se actualiza el valor. En el sentimiento se produciría un "quedar" peculiar, un quedar afectivo; y la inteligencia no sería una mera inteligencia sentiente, apoyada en la "sensación" (en la que se actualizaría la nuda realidad), sino una inteligencia afectiva, apoyada, además, en el "sentimiento" (en el que se actualizaría el valor y el disvalor).

Por mi parte, propongo llamar a esta posición filosófica un "inteleccionismo, pero bien entendido": un inteleccionismo que no es un "teoreticismo", porque cuenta con una intelección ampliada, que no es sólo teórica, sino afectiva. Y vemos que la teoría de Zubiri así reformulada queda ya muy próxima a la fenomenología de los valores, pues en esta última también hay una razón ampliada, que no es sólo razón teórica, sino razón afectiva y puede ser calificada, por tanto, como un "racionalismo, pero bien entendido".

Para terminar este ensayo, quizás convenga indicar que la lectura de Zubiri aquí propuesta no coincide con la interpretación más conocida de D. Gracia, según la cual Zubiri habría elaborado un "constructivismo" del valor, que sería una alternativa ética más interesante que el "intuicionismo" del valor scheleriano $(2013,125)$. Según Gracia, todo el bien, incluido el del hombre, quedaría situado en el nivel del sentido, ya que, aunque el bien queda indeterminado en la aprehensión primordial, es determinable en un proceso siempre abierto que transcurre en el nivel del logos y, como éste es el nivel de la construcción de sentido, el valor sería un sentido construido culturalmente, que por ello es capaz de hacerse cargo de las variaciones históricas y culturales de la ética.

Pero, en mi opinión, esta interpretación de Zubiri no resulta viable, pues si Zubiri se alejó de la fenomenología porque creía que la fenomenología había renunciado a la realidad a favor de un mero nóema como sentido, en ningún caso querría ver asimilada su propuesta filosófica a un constructivismo del sentido. Zubiri debe considerarse, más bien, como un filósofo intuicionista ${ }^{17}$, porque la realidad se da en un acto intuitivo, que es la aprehensión primordial, y sólo a partir de ella se funda el sentido. El logos es una "modalización ulterior" de la aprehensión, que explicita lo ya dado en aprehensión primordial, de manera que la intelección dual del logos presupone necesariamente la intelección simple de la aprehensión primordial. En los términos de Zubiri, el "campo" del que se ocupa el logos está ya dado en la

17 Sabemos que Zubiri evita hablar de intuición para marcar distancia con la fenomenología, pero reconoce el paralelismo entre la intuición fenomenológica y la aprehensión primordial de realidad (IL, 241). 
"aprehensión compacta de la realidad", que es la que luego va a des-compactar el logos, estableciendo las distintas respectividades entre realidades que posibilita dicha realidad compacta y aprehendiendo así lo real "campalmente"18.

Para cuestionar el intuicionismo de Zubiri, Gracia afirma que la "aprehensión de realidad" (o impresión de realidad) incluye dos momentos (2013, 94 ss.): la "aprehensión primordial" que sería un momento puramente formal (la formalidad de realidad) y el "contenido", que sólo se daría en el nivel del logos, y ya no en el de la aprehensión primordial. Así la aprehensión primordial de realidad se habría sustituido por la construcción de sentido ${ }^{19}$ y la filosofía de la realidad de Zubiri se habría convertido en una filosofía del sentido. De un sentido, debemos añadir, que ya no estaría fundado en la realidad, pues la formalidad de realidad aislada del contenido, que constituiría para Gracia el fundamento en el que se apoya el sentido, es un mero momento abstracto y es claro que esto no es una realidad-sino que sería, más bien, un peculiar sentido ideal-. Por ello ha de reconocer nuestro autor que en su propuesta interpretativa ya "no hay actos de aprehensión primordial", porque para que se produzca de hecho el acto de aprehensión primordial no basta el momento abstracto de la formalidad de realidad, sino que se necesita el contenido, que, según Gracia, no se da en aprehensión primordial.

Transcribo a continuación un texto de Zubiri que podría dar pie a la interpretación de Gracia, con el objetivo de ofrecer una lectura alternativa del mismo:

Lo aprehendido mismo tiene un contenido, pero tiene también la formalidad de realidad, del "de suyo". Esta formalidad es pues aprehendida en inteligencia sentiente. Pero su contenido es insuficiente. De ahí la necesidad de ir a lo que la cosa realmente es ${ }^{20}$. No vamos a la realidad, sino a lo que realmente lo real es. La raíz de esta nueva intelección es, pues, la insuficiencia del contenido (IRA, 342).

Cuando Zubiri afirma en este pasaje que la formalidad es aprehendida en inteligencia sentiente, pero que el contenido es insuficiente, creo que esto no significa,

\footnotetext{
18 El "logos" zubiriano recuerda al "juicio" de Erfahrung und Urteil, que, según Husserl, explicita lo ya dado en la experiencia, en la intuición.

${ }_{19}$ No sólo en el plano del valor, sino también en el de la nuda realidad; y es importante tener en cuenta que, en su argumentación sobre el valor, Gracia ha de recurrir explícitamente al nivel de la realidad para escapar al relativismo que implica el constructivismo del valor.

20 "Realmente" es un término técnico que se refiere conjuntamente al nivel del logos y la razón.
} 
como propone Gracia, que el contenido no es aprehendido (de modo que al no ser aprehendido tuviera que ser construido por el logos), sino que es el contenido aprehendido el que se muestra como insuficiente (debido a la respectividad de lo real). Por ello Zubiri comienza diciendo que "lo aprehendido mismo tiene un contenido", porque no puede haber aprehensión sin contenido, ya que sería una aprehensión de nada, es decir, no sería un acto de aprehensión. Debemos afirmar, por tanto, que el contenido se aprehende primordialmente, pues en la aprehensión primordial de realidad lo dado como real, gracias a la formalidad de realidad, es el contenido. Y la formalidad de realidad aislada del contenido no se aprehende; se aprehende el contenido dado en formalidad de realidad y así queda aprehendido también el carácter de "de suyo" que convierte el contenido en realidad, es decir, queda aprehendida la formalidad de realidad, pero no aislada, sino entendida como el de suyo del contenido.

Si esto lo aplicamos al tema del valor, vemos que resulta imprescindible contar con la donación del valor ya en el ámbito de la aprehensión primordial para poder iniciar el proceso constructivo del logos. Sólo si hay el valor dado en la aprehensión primordial, esto puede luego explicitarse en el nivel del logos y adquirir distintas concreciones construidas cultural e históricamente, sin que ese constructivismo caiga en un relativismo. Como dice Zubiri, en la aprehensión primordial se da una "insuficiencia" del contenido, debida a que la determinación última del contenido implica tener en cuenta la respectividad de lo real a todas las otras cosas reales. Por ello es necesario pasar al nivel del logos. Mas lo decisivo es que ha de tratarse de un logos no desligado de la aprehensión, porque él debe explicitar lo ya dado en la aprehensión primordial, o mejor, en las múltiples aprehensiones primordiales; $\mathrm{y}$, además, debe llevarnos de vuelta al nivel de la aprehensión ("de vuelta a las cosas mismas"), pues el logos siempre nos impele a buscar nuevas aprehensiones de realidad, que hagan posible una determinación cada vez más precisa de los contenidos. 


\section{Bibliografía}

Fernández Beites, Pilar (2012). "Razón afectiva y valores. Más allá del subjetivismo y el objetivismo”, en Anuario filosófico 45/1, 33-67.

Ferrer SAntos, Urbano (2010). El principio antropológico de la ética. En diálogo con Zubiri, Sevilla/Madrid: Thémata/Plaza y Valdés.

González Fernández, Antonio (1995). “Dios y la realidad del mal”, en Del sentido a la realidad. Estudios sobre la filosofia de Zubiri, Madrid: Trotta.

Gracia Guillén, Diego (2007). Fundamentos de bioética, Madrid: Triacastela.

- (2013). Valor y precio, Madrid: Triacastela.

Husserl, Edmund (I985). Ideen I: Hua III/1, Ideen zu einer reinen Phänomenologie und phänomenologischen Philosophie. Erstes Buch, Den Haag: Nijhoff [Trad.: Ideas I, México: FCE, 1985].

- (1985). Erfahrung und Urteil, Hamburg: Felix Meiner Verlag.

Ortega y Gasset, José (2004). Introducción a una estimativa. ¿Qué son los valores? (I923), Madrid: Encuentro.

Pintor Ramos, Antonio (1993). Realidad y sentido. Desde una inspiración zubiriana, Salamanca: Publicaciones Universidad Pontificia de Salamanca.

- (1995). "Intelectualismo e inteleccionismo", en Del sentido a la realidad. Estudios sobre la filosofia de Zubiri, Madrid: Trotta.

SCheler, Max (61980). Der Formalismus in der Ethik und die materiale Wertethik, GW, B.

2, Bern und München: Francke Verlag [Trad.: Ética, Madrid: Caparrós, 2001].

ZuBIRI, Xavier:

SH = Sobre el hombre, Madrid: Alianza Editorial, 1986. En concreto: "El hombre, realidad moral", capítulo 7, 343-444.

SSV = Sobre el sentimiento y la volición, Madrid: Alianza Editorial, 1992. En concreto: "El problema del mal" (1964), 196-320, y "Reflexiones filosóficas sobre lo estético" (1975), 321-392.

IRE = Inteligencia y realidad (primer volumen de la trilogía IS: Inteligencia sentiente), Madrid: Alianza Editorial, ${ }^{3} 1984$. 
$\mathrm{IL}=$ Inteligencia y logos (segundo volumen de IS), Madrid: Alianza Editorial, 1982.

$I R A=$ Inteligencia y razón (tercer volumen de IS), Madrid: Alianza Editorial, 1983.

SE = Sobre la esencia, Madrid: Alianza Editorial, 1985.

Este trabajo se encuentra bajo una licencia de Creative Commons ReconocimientoNoComercial-SinObraDerivada 4.0 